\title{
Internal Migration and Integration of Migratory Children in Gymnasiums of Durres
}

\author{
PhD. Cand. Nereida BALLA \\ Head master of basic school "Jusuf Puka”, Durres, Albania \\ balla.nereida@yahoo.com
}

\begin{abstract}
The aim of this study is to identify the problems that demographic movement has on children of displaced families from rural to urban areas. On this groundwork, the shock on the dimensions of the demographic shift in the level of adjustment is placed as well as children's education displaced to the outcomes of dismissing out of school. Viewed in this perspective, diverse nature of school problems factors and other characteristics that influence this phenomenon are shown. Instructors, students and parents' point of sight is practically brought through methodological argumentation of theoretical and empirical aspects reaching relevant conclusions. This field serves the governing bodies, policymakers and the public to address and improve the adaptation and teaching of this social rank, in prospect of the diversity and achievements in the educational process made by modern standards with all kids. This work concentrates on the variables of family functioning as good as its demographic characteristics, in cooperation with parents and teachers in some views of parent involvement in students' education. Founded on the theory the biological development teenaged Bronfenbrenner (1976), the subject of family environment (interaction of family members with each other) was rated of a great importance to education, in particular the cooperation of school staff with parents. Specifically, this study:- Determines the impact of teacher-parent relationship and vice versa, and in migration or no to the children of displaced families on school spirit.
\end{abstract}

Keywords: internal migration, migration management, training of children migrates, migrate adaptation of children, domestic migration policies, rates of internal migration and social issues

\section{Introduction: School culture as a result of migration}

We live in the modern society and it is necessarily that our divisions will be students who have different cultures (behaviors, habits, customs).

These different cultures being positive or negative have consequences in the school environments, such as:

1. Inclusion of students in learning and develops various activities classes.

2. Create opportunities for student interaction with each other not only in school, but also outside it.

3. Respect the students (when they speak, when give their opinion, when suggest)

4. Placing equal disciplines with more effectively by the teacher for students with different culture, ethnicity and different languages.

Inappropriate behavior comes from the fact that teachers or students do not interpret and respect the ethnic differences of students from dissimilar settings.

This study explores the relationships set up between teacher-students -parents trinomial, which are important in increasing the caliber of scholars not only in school, but also its reflection in our gild, which in a democracy has endured years of ups and downs its due to internal migration process. 
The principal line of the paper is that the city of Durres these 20 years has been a placing and overlapping chaotic societies coming from other regions of Albania that have created a different level by displaying the problems of attendance of pupils at the school also relations established between the school and parents.

Today development of the person is affected by the complexity of the premises where it goes in everyday of life. It is demonstrated that the larger involvement of parents to be in education, the child is more modern in every face. This engagement, in the fullest sense of the word, includes parenting. This concept does not mean to deny that education in the schoolhouse and the broader environment. These two views of instruction, with positive and negative effects of their own, tell us that parents and household are the priority in education. This is due to link large enough for kids with parents in early childhood, the fact that the parents (especially mothers) often cares how it will motivate their kid to school, books to be read, TV programs that will follow, friends with whom will live, and so on

This cannot be denied education schools, which gives students equal educational opportunities and creates a stable value system. Parents bear the responsibility to give themselves as partners to the school teaching of their kids. The success of students achieved $45 \%$ of his work, $30 \%$ of teachers and $25 \%$ of parents.

As the theoretical base of this subject serves the biological model (1979, 1997; Bronfenbrenner and Morris, 1998), which includes four systems that influence and interact in child development: microsystem, mesosistemi, ecosystem, and macrosystem. This example makes it clear that child development is linked up with micro-environments where he dwells, and mainly with family and school microenvironment. Grounded on this theory, which underscores the heavy impact that has on the child interaction in the family environment, and to study more deeply the influence of the family on academic achievement was used a theoretical framework of the family's Circumplex model (Olson, Russell, and Sprenkle, 1989) which is considered as the right framework to examine the operation of the family and to infer the dynamics within it. (Larner, 2004).

Granting to the family's Circumplex model (Olson, Russell, and Sprenkle, 1989), the operation of the family who then strongly affects the relationship with the school is associated with the three dimensions of household life; cohesion, flexibility and communication. The concept of cohesion reflects the emotional connection that members of the household are bearing. In other language, it shows their closeness or emotional distance, time passed together, ways to follow in making decisions, mutual interests and pastimes. Valuation of the above factors helps determine the level of family cohesion. Households with low cohesion, characterized by the concept of "emotional breakdown", and families with high levels of coherency, we accept the basic qualities a "solid" or families with "high consensus". (Olson, 1993).

Theory of overlapping spheres of Epstein $(1996,2001,2005,2011)$, is an opportunity to produce a clearer image of the diverse elements that influence family-school collaboration. Epstein, in concert with her colleagues believe that parental involvement can be gauged with six types which correlated with each other improve the learning achievements of kids and parental participation in instruction. They are:

Character 1 - skills and habits of their parents.

Character 2 - Communication.

Character 3 - Volunteering.

Character 4 - Learning at home.

Character 5 - Deciding to school.

Character 6 - Cooperation with community agencies (Epstein, etc. , 1997).

Flexibility is the ability to adapt, the ability to alter that system in terms of functionality family roles, relationships, rules established for the preservation of the relationship as reply to stress. It was set up that excessive flexibility leads to a chaotic household, while low flexibility leads to a real strong relationship (Olson, 1993). Family communication is assessed by looking at the family as a group, about the power to listen, ability to negotiate, to be blunt, clear, to show respect and 
attention to each other. Regarding this dimension of household life, Olson (1993) makes less determinations features, considering it good or miserable. The dimension of cohesion and flexibility, and ascertain the character of family communication dimension, regarded as critical (important) to facilitate the first two dimensions (Olson, 1993).

Digital Hoover-Dempsey and Sandler $(1995,1997,2005)$, helps us to understand the reasons why parents choose to be part or not in school activities and how it affects the construction of roles, parental feeling of being neat help your child succeed or opportunities and invitations offered by the school and the child itself to determine the type of parental involvement by these factors. Established on the hypothesis of the biological model of Brofenbrennerit $(1976,1986)$, but also on the effects of psychological and social fields, the researchers Hoover-Dempsey and Sandler (1995. 1997, 2005), represented a theory, which explain in detail what It motivates parents to be involved in education, listing several major causes:

- The context of the lifetime of the parents.

- Construction of personal parental role to transmit a model for parenting kids;

- To increase the sense of their power as parents to assist their kids to come after in school;

- Their reaction against the possibility that give both kids as easily as their schools to become affected in school spirit.

In a study counteracted by Jacobs and Harvey (2005), it was reconfirmed that family background variables have strong direct and indirect achievements of teenagers in school success. The variables analyzed in this survey are the family, household structure, maternal education level, aspects of paternal participation in the education of adolescents and parenting styles.

\section{1 How does family background in academic organization?}

Families migration is more prone to problems that occur among school-students-and parents, and this is ascribable to the new surroundings in which the family is located, the conditions facing the child in school and ability to adapt to society or to be Integrated into it.

Surveys indicate that the differences in socialization differences appear in the school achievements. Therefore, considering the family determines the mental development of children to reflect on their school accomplishments are brought into account several elements that are treasured by parents in different ways.

In this link the education point of parent education affects more than material conditions, although these two components are linked with each other.

Findings indicate that there is a significant connection between the terminations of the child in school and whether their parents are involved or not in school life. Therefore, the results of parents, children from socially excluded are mostly mediocre or below average compared with the consequences of ordinary parents' children which are mostly above average. Moreover, kids whose parents are involved in school, have better results than the average or excellent, compared with children of normal parents or those socially excluded. Consent of the high school and the results seem to correlate positively and significantly.

The higher the child's school results, much more likely It has that the number of records in his mansion to be higher. Half of the children who underachieve do not deliver any books at home. The largest number of books in the abode is more prevalent among parents involved in school life, compared with other parents. Most parents of socially excluded admit that they receive no books at home.

Most of these parents expect the youngster to be schooled at the university and beyond. Meanwhile, most parents expect socially excluded from their children receive school instruction (rather than general professional), so they are prone to giving a child apprenticeship. 
Parents involved in school spirit but also ordinary parents have hopes and aspirations optimistic about their children's instruction.

Most parents who belong to the category migratory child's school interested only in moments when he is named by the instructor or the kid of his battles.

This category of parents is often not be adapted to the friendly relations of the school and for different reasons family or job they forget each day more from the school their child allowing the latter to become contingent of tobacco, alcohol and finally abandon school.

The problems of children in most shells are a solution of 'parenting' lame '. (School psychologist, llija Polena)

Noting that nowadays parents belonging migratory families pay more care to employment and income protection. "They often define their material goods that offer their children and neglect the communication and support that claims to deliver a kid. Sensing this gap, the child reacts differently. Children take hold at the expense and encumbrance of their parents and it creates difficulties in shaping their personality.

Granting to the psychologist, the questionnaires made with pupils have come up these conclusions, the doubt of how easy you speak to your father about the problems they responded:

- They have easy "weep their problems" with fathers and $38.3 \%$ of adult males and $34.7 \%$ women.

While "find it hard" to communicate 16.8 percent of adult males and 32. 4 percent of adult females. More frequently than not, men report that they find it more comfortable to carry with their father's problems than female children. Meanwhile, in terms of communication with mothers showed that a larger number of adolescents are willing to speak with them. Most of the respondents, according to the psychologist's report that "it easy or very easy" to communicate with their mother, which shows that on the base of the cell family continues to be the mother the person who cares more for children who cares about those who talk more with them and to communicate more freely about all kinds of problems. Experts urge that a mother knows about the troubles of teenagers is a very positive potential in educational study with teenagers. It is for this intellect that in most cases forces us to enlist in this process as many mothers and parents in general.

A study conducted among sociologists, psychologists and students in some high schools of the city of Durres has been observed that, although the academic success of these students is somewhat predetermined by the influence of personal factors (family origin, economic status or educate parents) their school achievements strongly influenced by the work of teacher effectiveness.

A study between two groups of scholars with the same degree of intellectual and social, which prospered under that educates teachers.

Simply turn to these students are observed assessments based on their ethnic individuality.

In this way:

Of the 370 students surveyed, 147 of them have taken the overall learning of values and behavior of the majority culture, and have denied their ethnic culture.

Of the 370 students surveyed, 152 remain separate from society, and accompanied only by individuals of their ethnicity.

Of the 370 students surveyed 71 of these students try to uphold links with both civilizations, simply that this has caused problems in the way of behavior on their share.

Or maybe in this case we suppose that teaching should always bear the characteristics of society to which it belongs, or to extend the unique global values? 
The survey conducted showed that suburban schools of Durres and schools frequented the center, but $70 \%$ of pupils come from other districts show large differences in the level of academic achievement, and school attendance.

And here we highlight some elements that significantly involve the societal inequalities in suburban schools, such as:

\section{2 Social-cultural status of the family, after the child's success at school strongly influences baggage cultural knowledge and skills obtained in the menage.}

The high level of social-cultural creates the opportunity for the small fry to produce a positive picture on the societal side of his family, thus gaining confidence, trust in his forces and the livelihood of family and optimism to go ahead and to follow up on studies up to higher layers.

Pupils who attend secondary school of the city center had an intellectual development higher than kids who attended school in the city, because the environment that surrounded them was far more socialized and emancipated than the fringe.

Secondary school students coming from deprived environments, respect and appreciate more

More teachers starting from intellectual labor launched by the rational, the passion and method.

While the scholars belonging to assess more modest premises in preparation to help teachers and motivate and the interest they demonstrate for it.

Organization language skills appear more lively and diverse children from families with high cultural and appeared more resilient to children of families with a low cultural level.

From the answers it was observed that children's parents with basic school of education showed the difference in the maturation of their school accomplishments, because their parents do not carry into account some very important elements that should be valued as such:

- Natural processes of motivation in school performance.

- The possibility for additional knowledge to their kids.

- Determined to even out the child's language.

- Predisposition to learn.

- The nature of assistance offered to facilitate learning in different spots.

- The bulk of information on the child's mental growth.

- Predisposition to attend library etc.

- Nature of requirements dealing with what is awaited from the nature of the small fry.

It seems that the inclusion or exclusion of parents in school life significantly related to other aspects of school life such as child Pleasure in school or the child's school results.

- Children of parents who are typified in the school structures tend to want more school than children of average parents.

- On the other hand, children of parents from socially excluded tend to dislike school than children of other parents.

This finding led us to believe that children are more gratified with the school if their parents are taken in her spirit. 


\section{Education of parents and children is essential}

Works related to academic achievement, have repeatedly shown that instruction of parents is important in predicting the achievement of adolescents (Smith, Brooks-Gunn, and Klebanov's office, 1997).

Parents with high degrees of education enjoy the higher property status, but likewise are more taken in educational activities for youngsters. While children living in households with many kids (over 3 children), they are sorted out in the lowest strata of wealth, status, belonging mainly extended families, and considered vulnerable in terms of instruction, both at school. Within this class are classified migratory families that still save their traditions to have a family with many kids.

In them, suggested a positive direct connection of years of pedagogy of the parents, the students' achievements (Jimerson, Egeland, and Teo, 1999). Shaken up by this idea many researchers have studied how the teaching of parents affects the construction of the household environment (linvern, Brooks-Gunn, and Cohen, 2002; Yeung, linvern, and Brooks-Gunn, 2002), or in styles different parenting (Conger etc. , 2002; Mistry, Vanderwater, Houston, and McLoyd, 2002).

Maternal characteristics are another component that bears upon the academic and educational accomplishments of students (Eamon, 2005; Jeynes, 2001; Majoribanks 1996). Mothers with high degrees of education, have self-esteem, which impresses them to be more cooperative with teachers. This category of mothers with children who attain the highest loads in their school attendance. Besides, mothers who take kids into a relatively mature age, cognitive create a more stimulating surroundings and a supportive family environment, which sustains a positive outcome on the academic achievement of children (Eamon 2005).

Mothers with higher floor of instruction are more likely to enable the dynamic participation of teenagers in various courses, to manage more actively in their academic achievements and have more information about education than those with lower levels (Yonezawa, 2000).

Educated mothers surveyed use strategy to place herself in motion the inner energies of the child in such a style, that at that be familiar with the requirements, language, cultural universe that evaluates schools.

Families cultivated teenager stands for a greater intellectual maturity, it aspires not only to freedom of conduct simply for a higher moral autonomy, freedom of adults aiming to recognize and affirm themselves in life.

The families with adolescent rural backgrounds seem to express more bankruptcy, loss, receiving more individual loss since this is part of their everyday life in their environment socio-ethnic.

\section{1 Due to the current economic situation}

Inquiry on the influence of household income and academic achievement have shown that kids brought up in households with incomes significant financial and social resources have higher achievements, academic (Brooks-Gunn and Duncan, 1997; Magnusson, 2003; Marjoribanks, 2002; Yeung, linvern, and Brooks-Gunn, 2002; Sirin, 2005).

\section{Fit and groups.}

Scholars arrive to train with different parameters (physical, societal, economic, ethnic)

Academic life often directed towards a specific natural process between the person and the group within a certain category.

Acceptance of individual conduct and group behavior is determined by a number of elements which may be:

The existence of groups in the class (pressure on the student to whom the group will be allotted).

A stack of friends in class (of students influeca leader / positive or minus).

Grouping students into two streams (perceived instruction positively and negatively). 
Features that indicate these two streams.

\section{1 Independent Students}

Not part of any of the groups listed above

Their behavior is always under pressure to be attached near a group.

The larger the level of pressure the more difficult will be the independence of these scholars.

\section{3 Pupils attached to the group}

They at once subjected to group pressure being conformed completely, but often faced a different demeanor from that of themselves.

Behavior that he represents often creates a sensation of insecurity (requires keeping the equilibrium between personal principles and the rules of a group).

This issue of doubt appears in addictive behavior and an abnormal communication between pupils and instructors.

\section{3. 1 Psychological aspects}

The crisis of identity plays an important role in that as an adolescent I was able to see himself, desires, aptitudes and interests for the hereafter.

\section{3. 2 Motivation}

Where they find the point of reference, these adolescents? What are the patterns? How they are, positive or minus? As supplied and by whom, family or school.

Desire for education against incitement for education.

\section{3. 3 Society and its role in education}

At this crucial stage is "what friends say, to make friends, friends would judge me, whether I am part of the group? "

\section{3. 4 Social inequalities}

It is recognized that the educational achievements of pupils are different. The reasons are numerous and can be grouped according to biological and social agents.

Social inequality in the educational achievements of pupils through the mastery displayed unequal school culture. Before students get into the school or during it, it possesses a culture that is not one school.

This culture is acquired in the family, the neighborhood, the environment and can or not to be close to the school culture, it cannot well be conformed to it.

More difficult dimension of teacher-student relationship is the realization of equal treatment in schools, hence that all students regardless of the heterogeneity of social and ethnic lineage, the tier of knowledge of the public benefit equally.

According to Bernstein, addressing all pupils sit equal in rights and duties, nevertheless they are not really equal, school sanctions disparities start with its refinement. 
School culture that is transmitted is scheduled to be taken by scholarly people. And this embezzlement is different for different pupils.

Social inequalities are the consequence of the activity of social elements, but also the performance of the school foundation. They are ultimately a challenge to the school and society, because it is abundantly clear that education always bears the characteristics of society to which it goes.

How would that be, schools and the competent government agencies and institutions in the orbit of pedagogy at the local and central government should pay a greater attention by the parents through which they will enhance education teaching and strengthen awareness their right to education and better training of youth.

These finishes are the same man with researchers Vickers and Minke (1995) and similar to the researchers Boethel, (2003), Kohl, Lengua and McMahon (2000), Rimm-Kaufman, La Paro, Downer and Pianta (2005). Researcher Boethel, (2003), went even further in his study stating that not only that there is a positive relationship between co-teacher-parent and academic achievement, but cooperation is associated with other facets of maternal participation in children's training.

Attendance of pupils in school is not related significantly statistically cooperation, but communication and represents a weak negative correlation means that as the teacher-parent communication and cut down the number of absences that teenagers write in grades.

\section{RECOMMENDATIONS}

- For a proficient execution of this procedure must have teachers and parents around the objective deeply and organic link which enhances the character of students.

-When parents are participating in school problems, they are open to requests, comments, grievances they may have against teachers. Clarification of parents of different troubles that they experience anxiety, takes time, patience and a sound knowledge of cooperation.

-Include parents in the assessment of pupils means extends further than getting a flyer reporting, then they ask to look current examples of child labor for a certain point of time. Parents create a more perfect impression of their child's advancement.

-All parents have to look themselves in the role of teachers to supervise and promote the learning of the youngster. Read scripts and then talk together with your kids.

- Undertake continuous training of teachers and parents for mutual cooperation.

- To conduct trainings, discussions and exchange of experiences between local parents and those who are migrating, local and migrant students and teachers a long experience in this area.

- To organize meetings through roundtables, where participants will be parents, teachers, scholars.

- To hold conferences on the topic: "The role of parents in the education system".

- Develop questionnaire for the assessment of accounts on school triangle: students, instructors, parents;

- The finished forms for workers and parents in school activities;

-To produce various important meetings.

- Build up and accurately carried out an annual activity plan in cooperation with the Council Presidency parents -teachers, hence that the interest of parents in school spirit and work to be more efficient. 
-In the new curriculum it is imperative that each school should prepare a set of policy suitable for parental participation in instruction.

The drafting of such insurance, together with the respective program for parental participation in education is very important, because this thing benefits students, teachers (school) and parents.

Bibliography

1. Bronfenbrenner, U. (1997). Ecology of the family as a context for human development: Research perspectives. Developmental Psychology, 22, 723-742.

2. Brooks-Gunn and Duncan, 1997

3. Epstein, J. L. (2011). School, family, and community partnerships: Preparing educators and im-proving schools (2nd ed. ). Philadelphia, PA: Westview Press.

4. Epstein, J. , Coates, L. , Salinas, K. , Sanders, M. , \& Simon, B. (1997). School, family and community partnerships: Your handbook for action. Thausand Oaks, CA: Corëin.

5. Epstein, J. L. (1986). Parents' reactions to teacher practices of parent involvement. ElementarySchool Journal, 86, 277294.

56Epstein, J. L. (1992). School and family partnerships. In M. Aiken (Ed. ), Encyclopedia of educational research (pp. 11391151). New York: MacMillan.

7. Epstein, J. L. (2001). School, family, and community partnerships: Preparing educators and improving schools.

8. Hoover-Dempsey and Sandler (1995. 1997, 2005),

9. Magnusson, 2003

10. Marjoribanks, 2002

11. Muller, C. \& Kerbow, D. (1993). Parent involvement in the home, school, and community. In B. Schneider \& J. S. Coleman (Eds. ), Parents, their children and schools (pp. 13-39). Boulder, CO: Westview Press, Inc.

12. Olson (1993)

13. Vickers and Minke (1995) 